\title{
The Unjustified Increase of Wealth, the Tax Evasion and the Taxable Capacity: The Peruvian Case
}

\author{
Gonzalo Alonso Escalante Alpaca ${ }^{1,2}$ \\ ${ }^{1}$ Law and Political Science Department, Saint Paul Catholic University, Arequipa, Peru \\ ${ }^{2}$ Tax Advisory, Zegarra Aguilar Attorneys at Law, Arequipa, Peru
}

\section{Email address:}

gescalante@zegarralaw.com

\section{To cite this article:}

Gonzalo Alonso Escalante Alpaca. The Unjustified Increase of Wealth, the Tax Evasion and the Taxable Capacity: The Peruvian Case. International Journal of Law and Society. Vol. 4, No. 3, 2021, pp. 187-192. doi: 10.11648/j.ijls.20210403.15

Received: August 3, 2021; Accepted: August 13, 2021; Published: August 23, 2021

\begin{abstract}
The pandemic brought serious consequences on the health of people but also on their economy, which has led to some new business initiatives which not always comply with the tax legislation. The unjustified increase of wealth (UIOW) arises as the legal response to the difference between the wealth that has been considered by a natural person (NP) on the corresponding tax return and the wealth that has been proved to exist by the Tax Administration (TA) but has not been considered on any tax return. In order to apply the UIOW figure it is necessary that such difference lacks of any justification that could prove to the TA that the increase of wealth identified is non-taxable or either that it has already been considered on a previous tax return. As it is evident, the UIOW is a mean provided by the legislation for the TA to fight against tax evasion. Therefore, it is necessary to clearly comprehend which is the fundament for the UIOW to be part of the Peruvian Income Tax Law (PITL). For the current analysis, the legislation, doctrine and jurisprudence have been considered. This has allowed us to conclude that the taxable capacity principle is such fundament since it depends on the factually verified wealth that a certain NP externalizes in order to establish the corresponding taxable consequences, constituted on the present case by the UIOW.
\end{abstract}

Keywords: Unjustified Increase of Wealth, Evasion, Presumption, Taxable Capacity

\section{Introduction}

The world is facing circumstances that seemed unimaginable no more than a couple of years ago and that have come as a consequence of the pandemic that has brought not only several human loses but has also affected the normal development of economic activities. The latter has meant for many NPs to lose their jobs or to see their income reduced, which has led them to reinvent their income source through different activities.

Such activities, for various reasons, may not be completely formal from the tax legislation point of view implying that the NP obtains more income than the one considered in the corresponding tax return, or even that there is no tax return at all. Considering this is the current situation there is a whole new mass of people, added to those who did not filled any tax return since before the pandemic, whose income is not formal according to the Tax Law.

The UIOW is a legal figure contained in the PITL which allows the TA to presume that the difference between the wealth consigned on a tax return and the one verified by this entity configures a net income from a certain NP. This in order to fight against tax evasion among other objectives.

Therefore, the UIOW figure regains its validity in Peru, because the quantity of NPs that are subject to have their income increased under the reach of this concept has grown in numbers since the economic stagnation started with the health emergency. It is then necessary for a profound analysis to take place regarding the UIOW configuration as well as the effects of its application, since its effects are regulated as a presumption in the PITL that allows the TA to consider the unjustified wealth as net income of the NP subject to a tax audit.

The aforementioned analysis will allow us to determine if the taxable capacity is the fundament on which the UIOW relies on for its inclusion in the Peruvian Tax Law, since this could be the element that sustains the presumption that a net income has been perceived by the NP that is unable to prove that the identified difference between the wealth consigned in the tax return and the one factually verified by the TA has 
been part of a previous tax return or that it corresponds to a non-taxable concept.

We have not identified any study that focuses on the relation between the taxable capacity, the UIOW and the presumption that comes as a result of its configuration.

For the present analysis, our hypothesis is that the taxable capacity principle is the pillar that sustains the inclusion of the UIOW figure in the PITL, since it allows to establish the taxable consequences that apply when a NP has not included in its tax return the total wealth that has been identified by the TA, and is the principle that ultimately supports the fight against tax evasion, as well as the equality principle from which the taxable capacity principle derives from.

The present investigation is of the legal - propositional kind, regarding the taxable capacity principle and its relation with the UIOW figure. The method used is the hypothetic deductive to establish whether the suggested hypothesis turns out to be true or not.

The study is divided in four sections. The first one corresponds to the presumptions in the Peruvian Tax Law; the second one regards the tax evasion and its relation with the UIOW; the third one considers the constitution of the UIOW figure and the consequences of its application; and finally the fourth one analyses the taxable capacity principle and its relation with the UIOW.

\section{Presumptions in the Peruvian Tax Law and Its Relation with the UIOW}

\subsection{Presumptions in the Tax Law}

Presumptions are an important part of the Peruvian tax legislation since they allow the TA to establish the taxable consequences regarding a taxpayer just from the existence of a proven fact that according to the legislation implies the configuration of a taxable fact.

On this matter, Delgado points out the following: [1] "Actually, the presumption is a logical process according to which, if there is a known and proven base fact, a statement of another fact is concluded - the presumed or inferred fact - on which certain legal effects are projected. The process of logical deduction can be derived from the application of the rules of experience by the person applying the law (simple presumption or hominis) or they can also be established in the legal norm (legal presumption)".

On his side, Bravo indicates that the presumptions can be of two kinds, relatives and absolutes. This according to the following detail: [2] "The legal relative presumptions, the ones that by tradition are called iuris tantum, are those that admit contradictory proof. The legal absolute presumptions, called iuris et de iure, are those which do not admit contradictory proof."

Regarding this subject, Fernández indicates that: [3] "Presumptions in Tax Law are of great importance for the State, since they help the Tax Administration to avoid the activity of having to demonstrate, due to the difficulties that arise in this regard, the probable and uncertain intention of defrauding the Tax Administration of a few taxpayers. But by reason of those few cases in which a taxpayer tries to omit income, it elaborates a presumption elevated to a general rule, that comes to apply not only to those who have tried to deceive the Tax Administration, but also to those who have acted in good faith, for the sole reason that some facts, acts or situations that may give rise to the birth of an obligation in favor of the treasury can be easily hidden by the taxpayer through the preparation of false evidence."

Considering the previous comments, we can mention that the presumptions must be understood as solutions of a positive nature that are inserted within the legal system to enable the TA to resolve situations in which, based on a fact verified in the phenomenal world, a tax consequence is attributed to it, since there is a logical nexus that allows the TA to presume the configuration of such consequence.

\subsection{The Tax Presumptions and the UIOW}

As a preamble to the analysis of the presumptions and their connection with the UIOW, we quote Arenas who points out the following: [4] "The tax audit of natural persons has become a constant act in our system, due to the enormous difference found after analyzing the income consigned in the tax returns, the wealth obtained and the consumption made by taxpayers and non-taxpayers, the same ones that in most cases do not keep relation between them, having an adverse effect regarding the need to collect resources by expanding the tax base and reducing evasion levels, promoting formalization and achieving adequate compliance with the tax obligations by natural persons, SUNAT has developed a Program of Inspection of Natural Persons for Unjustified Increase of Wealth."

We understand, as the aforementioned author, that the tax audit of the UIOW is an effort made by the TA in order to encourage the formalization of NPs that do not comply with including their income or partially including it in the tax return in order to reduce the economic impact that the configuration of the taxable act means to them. Since the UIOW is configured as long as the origin of the difference on the wealth consigned in the tax return cannot be supported by the taxpayer, it is through the assignment of this legal figure that the TA manifests its power to determine the tax debt on the basis of a proven fact, such as the existence of a wealth increase that lacks of justification.

The UIOW attribution is therefore, the response that the tax legislator has found to face the tax informality in order to enable the TA to establish tax consequences to the differences that are identified between the income included in the tax return and the externalized wealth. This externalization can be configured through income, consumption or the accrual of assets by the taxpayers. Such attribution must come as a result of an audit procedure carried out by the TA.

Regarding the UIOW, the article 52 of the PITL establishes a negative evidentiary rule indicating which means are not suitable to support the origin of the wealth difference identified by the TA. This article enshrines the following text: [5] "It is presumed that wealth increases whose origin cannot 
be justified by the tax debtor, constitute net income not declared by him. Wealth increases may not be justified with: a) Donations received or other liberalities that do not appear in a public deed or other reliable document. b) Profits derived from illegal activities. c) The entry into the country of foreign currency whose origin is not properly supported. d) The income perceived that was at the disposal of the tax debtor but that had not been disposed of or collected, as well as the balances available in accounts of entities of the national or foreign financial system that have not been withdrawn. e) Other income, among them, those from loans that do not meet the conditions indicated in the Income Tax Law regulation."

Regarding this article, the TA indicates through the Report 039-2021-SUNAT/7T0000 that: [6] "According to the aforementioned norm, the increase that a person had in its wealth, whose origin is unknown as it was not supported by it, gives place to a legal presumption by which said increase is considered undeclared net income for the application of the income tax."

Therefore, the UIOW gives places to a iuris tantum presumption, as the legislative response that allows the TA to determine the amount of the tax obligation that corresponds to the taxpayers as a result of the identification of a wealth increase regarding which the taxpayer has not been able to support its origin.

The TA through its faculty to audit the real wealth of the taxpayers is allowed to consider that the difference that could not be supported during the tax audit procedure as an UIOW is presumed to be a net income subject to taxation through its addition to the net labor income of such taxpayer on the fiscal year in which the UIOW is identified. This addition is sustained on the article 60 of the PITL Regulation.

According to the PITL, it is presumed that the wealth whose origin cannot be justified is originated in the taxpayer's intention to avoid the taxable consequence applicable. Under these circumstances the taxable consequence applies as a direct effect of the identification of the UIOW.

The Peruvian Tax Court (PTC) establishes the following mandatory criteria regarding the UIOW consigned on the sentence 04761-4-2003: [7] "The income omitted from the tax return that constituted taxable income, detected in the audit procedure, whose origin has been determined by the Administration, are part of the taxable income for the purpose of determining the Income Tax, and consequently are excluded with the income consigned in the tax return, in order to determine the unjustified increase of wealth."

This sentence allows us to understand that, for the verified wealth to be considered as an UIOW, it is necessary that its origin cannot be identified by the TA.

\section{Tax Evasion and the UIOW}

\subsection{Tax Evasion}

It is important to begin with this part of our analysis quoting Ruíz de Castilla who defines the evasion as it follows: [8] "Evasion is a taxpayer's behavior that is characterized by direct non-compliance with the tax law. Tax evasion receives the legal treatment of a tax crime."

The way in which the quoted author conceptualizes the tax evasion seems to us quite adequate and applicable to the Peruvian reality, considering that there are not few cases in which the taxpayers act against the tax legislation in order to reduce or eliminate the taxable impact of its operations. The legal figure of the taxpayer has to be understood as the subject who carries out the events that generate tax obligations, this qualification is attributable both to the person who has considered any income or not for the purpose of determining the applicable tax. This is in accordance with the definition contained in article 9 of the Tax Code (TC).

We must be clear on the fact that the tax evasion is not configured only when a taxpayer completely omits the declaration of taxed income or uses third parties to hide the real economic magnitude of its activities, but also when it resorts to fraudulent practices that allow the subject not to consigned all of its income in the tax return. Therefore, it is possible for the tax evasion to have absolute or partial effects on the tax obligation included in the tax return.

The Peruvian Criminal Tax Law (PCTL) defines on its article 1 the tax fraud as it follows: [9] "Whoever, for his own benefit or that of a third party, using any artifice, deceit, cunning, ruse or other fraudulent form, fails to pay completely or partially the taxes established by law, will be punished with prison from 5 (five) to 8 (eight) years and with 365 (three hundred sixty-five) to 730 (seven hundred thirty) days-fine."

The PCTL also establishes on its article 2 the types of tax fraud with the following detail: [9] "The types of tax fraud repressed with the penalty of the previous article are: a) Hide, totally or partially, assets, earnings, income, or record totally or partially false liabilities, to cancel or reduce the tax to be paid. b) Failure to deliver to the tax creditor the amount of the withholdings or perceptions of taxes that have been made, within the period established by the relevant laws and regulations."

Regarding this subject, Alpaca indicates that: [10] "Although these concepts have as a common element the fact of expressing the same objective (to stop paying taxes totally or partially), it is possible to affirm that (...) tax fraud (which is also classified in the doctrine as tax evasion or fiscal evasion) is characterized by non-payment of the tax obligation through the use of fraudulent means - harmful enough to be legally criminally relevant (...)."

The tax evasion is considered in our legal system under the figure of tax fraud. Thus, evasion must be understood as the fraudulent act or acts that materialize the will of the taxpayers to hide the configuration of a debt in favor of the treasury, seeking to prevent the TA from identifying the existence of the taxable fact completely or partially.

\subsection{The Tax Evasion Related to the UIOW}

Among the evasion types described in the PCTL, the one that concerns us in this analysis is the one described in subsection a) of article 2 of the aforementioned regulation. This subsection is where the total or partial concealment of 
income or assets is considered as a mean to extinguish or reduce the tax burden as a form of tax evasion or fraud.

On this subject the TA has issue the Report 039-2021-SUNAT/7T0000, which analyzes the scope of articles 1 and 2 of the PCTL regarding the configuration of the UIOW, noting the following: [6] "In this sense (...), if as a result of an audit procedure carried out by the Tax Administration, a net income is determined for an unjustified wealth increase, the crime of tax fraud will only be configured in the mode of concealment of income referred to in articles 1 and 2 of the PCTL as long as it is determined that a tax has not been paid, through the use of fraudulent forms, completely or partially."

Therefore, considering the pronouncement of the TA, we have that the UIOW configures a tax crime, as long as fraudulent practices are used by the NPs to avoid completely or partially being within the range of supervision of the TA with respect to the existence of a tax debt, thus eroding the tax base in our country. When the taxpayers do not incur in fraudulent practices, they will be susceptible to the imputation of legal consequences of an administrative nature, not a criminal one.

\section{Constitution of the UIOW}

\subsection{The Application of the UIOW}

As the UIOW has as a consequence a presumption that implies considering as net income for the determination of the tax obligation the wealth difference identified regarding a taxpayer that lacks of support, it is necessary to analyze how the TA determines the existence of such difference that leads to the attribution of the UIOW. This taking into consideration that the article 52 of the PITL already mentioned, allows us to have a clear understanding of the evidentiary means that are not suitable to support the wealth difference identified by the TA.

On this matter, the subsection d) of the article 60 of the PITL Regulation establishes that the methods to determine the existence of the UIOW are: [11] "1. Balance plus Consumption method: It consists on adding consumption to the wealth variations for the fiscal year; 2. Acquisitions and Disbursements Method: It consists on adding the acquisitions of goods, for consideration or free of charge, the deposits in the accounts of entities of the financial system, the expenses and, in general, all the disbursements made during the fiscal year. Likewise, acquisitions and deposits from loans that meet the requirements referred to in Article 60 -A will be deducted. In the case of assets and deposits in accounts, it is not necessary to distinguish whether these are reflected in the equity at the end of the fiscal year. As disbursements will be considered, even, the money provisions for payments of consumption made through credit cards, loan installments, payment of taxes, among others, will be computed. The disbursements made for the acquisition of goods considered in the first paragraph of this numeral will not be computed."

\subsection{The Duty to Sustain the Wealth Regarding the UIOW Identified by the $T A$}

For the attribution of the UIOW an audit procedure must take place first, where as a consequence of the application of any of the methods provided in subsection d) of the article 60 of PITL Regulation previously mentioned, the existence of a wealth difference is identified. As a consequence of the identification of the UIOW the duty to sustain the origin of the wealth difference relies on the taxpayer who must adequately sustain the cause of the difference and that the equity that corresponds to it has been included in the corresponding tax return, in case this applies.

Thus, the duty to sustain the wealth difference rests exclusively on the taxpayers, since the TA will base the attribution of the UIOW on the existence of such difference. The taxpayers have the responsibility to prove that the presumption of the TA is not in accordance with the Tax Law. All this on the basis of the presumption that such wealth has not been included in the tax return, and it is the taxpayer's exclusive responsibility to prove that the wealth was informed or that it is not a taxable concept, and therefore that it does not constitute an UIOW.

\section{The Taxable Capacity and the UIOW}

\subsection{The Taxable Capacity}

The taxable capacity constitutes a principle linked to the principle of equality regulated in article 74 of the Peruvian Constitution (PC), as it provides that the allocation of a certain tax burden is made in proportion to the wealth generated by a taxpayer as it implies the externalization of such capacity.

The taxable capacity is an inherent requirement to the application of a certain tax burden related to a taxpayer. The Constitutional Court (CC) in the sentence issued in the file STC 2727-2002-AA/ TC indicates that: [12] "Likewise, (the principle of non-confiscation) is directly connected with the right to equality in tax matters or, what is the same, with the principle of taxable capacity, according to which, the distribution of taxes must be carried out in such way that equals should receive an equal treatment and those subjects in unequal conditions should receive an unequal treatment, so that the tax burdens must apply, in principle, where there is wealth that can be taxed, which obviously implies that the personal or patrimonial capacity of the taxpayers is taken into consideration."

Regarding the constitutionality of the principle of economic capacity (taxable capacity), Gamba mentions the following: [13] "The Article 74 of the PC does not "expressly" recognize "economic capacity" as an applicable principle in tax matters, a situation that should not lead us to affirm that this is not enforceable, since, its content can be derived without major difficulties from the "principle of equality". For this reason, the lack of an express recognition of the principle of economic capacity in article 74 of the PC, cannot lead us to the absurd of considering that it does not have full force in our tax system or that it is a principle available to the legislator. On the contrary, we consider that a law that violates the principles of equality 
or non-confiscatory nature - expressly recognized by the constitutional text - is so unconstitutional, as a law that does not satisfy the requirements established by the principle of economic capacity - derived from the principle of equality -. In addition to this, there have been multiple cases in which our Constitutional Court (CC) has obtained important practical effects derived from the principle of economic capacity, when carrying out the control of the constitutionality of the tax laws (through unconstitutionality actions), as well as when deciding on specific cases (through guarantee actions)."

Caliendo details the taxable capacity as: [14] "The objective scope of the principle of taxable capacity is characterized by being a principle oriented especially to the ordinary legislator. In this way, if the legislator chooses facts that do not manifest a presumptive sign of wealth, this election is tainted by the vice of unconstitutionality."

Tarsitano conceptualizes the taxable capacity by noting the following: [15] "The taxable capacity is the ability of a person to be a taxpayer of tax obligations insofar as they are called to finance public expenses by the disclosure of manifestations of wealth (economic capacity) that, weighted by legislative policy, are elevated to the rank of taxable. Our thesis is that the taxable capacity justifies the structural autonomy of the tax and financial law."

Therefore, the taxable capacity must be understood as a constitutional principle according to which the obligation to assume a certain tax burden exists as long as the passive subject of the tax obligation manifests the ability to assume the tax burden. The manifestations of the taxable capacity can be configured through the existence of income, consumption or the accrual of assets. The existence of such manifestations imply that the person is susceptible to be considered as a taxpayer by the TA since it has been proved that the subject has incurred on the requirements established on the Tax Law in order to qualify as such.

\subsection{The UIOW and Its Relation with the Taxable Capacity}

Since the UIOW is a legal response against the taxpayers who have not fulfilled the obligation to include in the corresponding tax return its complete obligation we need to understand that the attribution of the UIOW depends on the manifestation of a certain taxable capacity by the taxpayer.

These manifestations are constituted by the existence of a difference of the wealth consigned in the tax return and the wealth identified by the TA whose origin could not be sustain by the taxpayer during the audit procedure. As the taxpayer has externalized income, consumption or the accrual of assets during the fiscal year, but it has not been able to demonstrate without a doubt the origin of the wealth used to incur in such manifestations of taxable capacity, the tax consequences will be triggered, implying that the UIOW will be considered as net income which should be added to the net labor income in order to determine the debt in favor of the TA.

Those manifestations of the taxable capacity by the taxpayer are the requirement that needs to be fulfilled before the TA attributes the existence of the UIOW. If those manifestations did not exist, no UIOW would be constituted since no taxable capacity would be proven to sustain the application of such taxable consequence.

It is also necessary to consider that the taxable capacity sustains as well the fight against tax evasion, because it allows the TA to follow the track of the aforementioned manifestations to determine if those are only subject to taxable consequences or that also criminal consequences apply.

\section{Conclusions}

The presumptions included in the Peruvian Tax Law allow the TA to apply a taxable consequence considering the existence of a logical nexus regarding such presumptions with a proven fact.

The UIOW leads to a relative presumption since it is allowed for the taxpayer to sustain the origin of the wealth difference identified by the TA.

The attribution of the UIOW will qualify as tax evasion if the taxpayer has incurred on fraudulent practices to avoid the tax burden applicable to its operations.

The UIOW will be constituted as long as the difference of wealth cannot be sustained by the taxpayer to be consigned on a tax return or a non-taxable concept.

The taxable capacity principle implies that a tax burden can be applied as long as the taxpayer has externalized the existence of a determined economic capability.

The taxable capacity principle sustains the fight against tax evasion as well as the application of the UIOW since the proven taxable fact has been concealed by the taxpayer.

The application of the UIOW implies the existence of a taxable capacity externalized by the taxpayer, since it depends on such requirement for the corresponding taxable consequences to be applicable.

\section{References}

[1] Delgado. C. (2004) Approaches to the regime of imputed income in the Income Tax law: limits and perspectives. VII National Conference on Tax Law: Scope of application of the Income Tax in Peru. Peruvian Institute of Tax Law. (Lima, Peru) 14.

[2] Bravo. J. (2015). Tax Law Fundaments Fifth Edition. Jurista Editions. (Lima, Peru) 364.

[3] Fernández. A. (2019). Tax Presumptions on the book Contitutional Tax Law. Legales. (Lima, Peru). 1168.

[4] Arenas. C. (2021) The face of taxation in Peru, on the book Ibero-american Tax Law Treaty. Pacific Institute. (Lima, Peru). 168-169.

[5] Peruvian Income Tax Law, approved by Supreme Decree 179-2004-EF.

[6] Tax Administration Report 039-2021-SUNAT/7T0000.

[7] Tax Court sentence 04761-4-2003.

[8] Ruíz de Castilla. J. (2013). Economic theory applicable to taxation. Available http://blog.pucp.edu.pe/blog/franciscoruiz/. 
[9] Peruvian Criminal Tax Law, approved by Legislative Decree 813.

[10] Alpaca. A. (2015). Tax and Customs Crimes. Ubi Lex Editions. (Lima, Peru). 200.

[11] Peruvian Income Tax Regulation, approved by Supreme Decree 122-94-EF

[12] Constitutional Sentence issued on the file STC 2727-2002-AA / TC.
[13] Gamba. C. (2014). About the TTNA and the economic capacity. A "conformity" difficult to understand. Regarding the Constitutional Court $\mathrm{N}^{\circ}$ 03797-2006-PA/TC, on the book: Tax investigations and fiscal policy Volume 1. Grijley. (Lima, Peru). 188.

[14] Caliendo. P. (2018). Tax Law and the economic analysis of law. Grijley. (Lima, Peru). 389.

[15] Tarsitano A. (2014) The Taxable Capacity Principle as fundament of the financial constitution. A doctrinal and jurisprudential vision. Law \& Society 43. (Lima Peru) 121. 